\title{
Orthogonal Moment Extraction and Classification of Melanoma Images
}

\author{
Sudhakar Singh ${ }^{1}$, Shabana Urooj ${ }^{2}$ \\ ${ }^{1,2}$ Department of Electrical Engineering, Gautam Buddha University, Greater Noida, India \\ sudhakarsingh86@,gmail.com ${ }^{1}$, shabanaurooj@ieee.org $^{2}$
}

Abstract: This paper provides orthogonal moments (OM) such as, Zernike Moments(ZM), Psuedo Zernike Moments(PZM) and Orthogonal Fourier Mellin Moments(OFMM) for the analysis of melanoma images. The moment invariants may vary with respect to geometric variations. For the analysis of orthogonal moments hundred random melanoma images and hundred non-melanoma images have been taken into consideration from the database of 570 melanoma images and 250 non-melanoma images respectively. Orthoganal moments have been computed by varying the phase angles from $10^{\circ}$ to $40^{\circ}$ with an equal interval of $10^{\circ}$ degree for the orders 2 , $4,8,16,32,64,128,256$ respectively. For the optimal OMs Particle Swarm Optimization (PSO) technique have been used. These set of extracted optimal OMs have been further applied to classify melanoma images. Support Vector Machine (SVM) has been used for the classification of $[1]$ sensitivity $=88.78 \%$.

Keywords: Moments Invariants, ZM,PZM, OFMM, SVM, PSO.

\section{Introduction:}

Melanoma is a most widely recognized skin disease around the world, and its rate is increasing endlessly[1] [2]. Computational analysis frameworks have been developed to help dermatologists in right time for the early diagnosis of skin disease from dermoscopy images[3]. Skin diseases like tanning, pigment darkening, sunburn, skin cancers, and infective diseases are rising at a more speedily due to litter, ultraviolet light, and global warming. A one percent decline in ozone leads 
to a $2-5 \%$ boost in the prevalence of skin cancers and other related disease[4]. Computer Aided Detection (CAD) [5] [6]can be used on the skin disease images to assist the skin expert radiologist as a subsequent reader. CAD can find and differentiate the skin disease that a skin disease expert may not sprout[7] [8]. Figure 1 represents the distribustion of diseases in india.

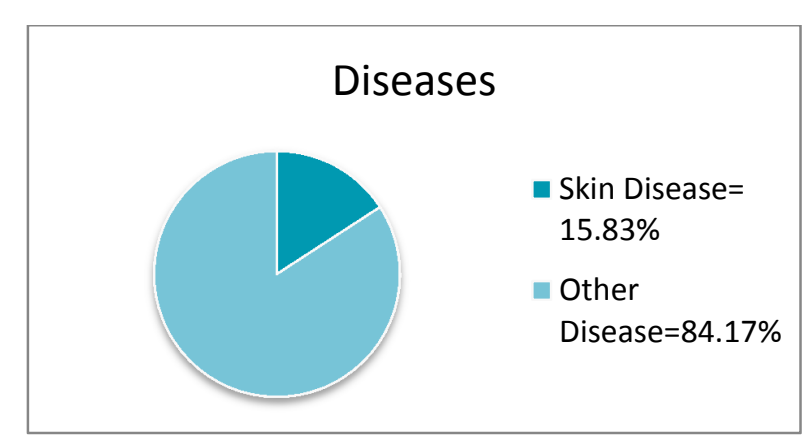

Figure1: Distribution of Diseases

In image investigation pattern recognition [9]texture classification [10]image indexing and target direction assessment, OMs played very important role.

The article presents classification of melanoma images using OMs. There are very few articles which have been used OM features for the classification of images. The performance of the proposed method is better than other existing techniques. OMs are non-redundant features so less number of features are required for better melanoma classification, and hence reduced the computational complexcity.

The paper is arranged in six sections, first section deals with introduction part of the paper, second section introduced the orthogonal moments, section three explains about the moment selection 
technique, section four deals with the classification technique, section five for the result discussion ,section six summarize the paper.

\subsection{Background}

Orthogonal Rotation-Invariant Moments (ORIMs) are very significant features for imaging. Moments hold important data in images, and they are invariant to image moment. ORIMs contain Zernike Moments, Pseudo-Zernike Moments, and Orthogonal Fourier-Mellin Moments (OFMMs) [11][12]. Zernike moments, was planned by Zernike in 1934 as the eigenfunctions of differential equation . Zernike moments can also be produced from Legendre polynomials with firm constraints 1954, found by Bhatia and Wolf in 1954. Sergio Dominguez [13] proposed a technique for the recognotoin of 3-D object and pose analysis. Chandan et al.[14] proposed a technique for the error computation, Sheng et al. proposed OFMMs[15]-[18] for pattern recognition. The amounts of Orthogonal moments are invariant to the variation of the signal[16]. Orthogonal moments are digitized together geometrically on the unit disk and numerically in the orthogonal function values for imaging applications[6][11]. Certainly, a bundel of pixels are designated to cover the unit disk and a value is allocated for each orthogonal function and each selected pixel[20]. Straight methods determine the orthogonal function value for a pixel by directly sampling the functions at one or several locations of the pixel[21].

In image investigation, pattern recognition [9]texture classification [10],image indexing and target direction assessment OM played very important role. Orthogonal moments[7], [10], [22], [23] are noise resistant [6] and are used as a basis to create moments with new belongings. Few additional efforts have been made to decline computation time of the orthogonal moments[24]. However, digitization negotiations the precision of the orthogonal moments. Two types of errors had been 
identified direct method in digitization. The first error derives from the approximation of the continuous unit disk by a finite set of pixels, called geometric error. The second error is after sampling orthogonal functions.

It is denoted as the numerical error. If pixel size would be small then numerical error would be small [16]. Liao and Pawlak proposed a method for selecting the radius of the disk and thus the number of pixels to control the geometric error, numerical error when determining the orthogonal function values[21].Rrecently, Xin et al. developed a technique to compute Zernike moments in polar space [21]

\section{Methodology}

Figure 2 shows flow-chart of proposed methodoly. First step is to pic the images from standard ISIC database[6] and pre-process and normalize the image then OMs of the image have been computed, these computed momets are optimized by PSO and the classified by SVM.

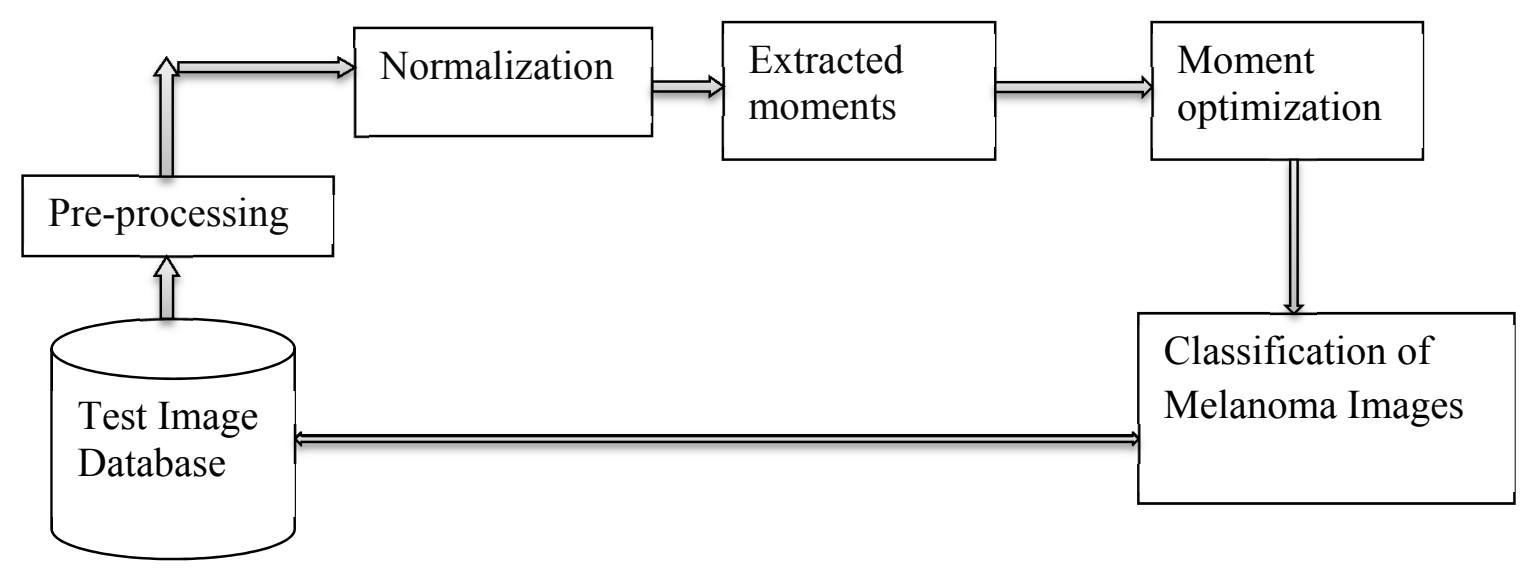

Figure 2: Flow chart of proposed methodology 
Image function $f(j, k)$ is defined in four-sided engagements of pixels with $i$ represents rows and $k$ represents shows

Therefore, the ORIMs are defined for image function $f\left(x_{j}, y_{k}\right)$ as follows

$A_{m, n}=\frac{p+1}{\pi} \sum_{j=o}^{N-1} \sum_{k=0}^{N-1} f\left(x_{j}, y_{k}\right) V_{m, n}^{*}\left(x_{j}, y_{k}\right) \Delta^{2}$

Here $\mathrm{m}$ is non-negative integer, $\mathrm{n}$ is integer and $V_{m, n}^{*}(x, y)$ is comlex conjugate of $V_{m, n}(x, y)$ moment basis function $V_{m, n}(x, y)$ can be defined as below

$V_{m, n}(x, y)=R_{m, n}(\rho) e^{j n \theta}$

where $\rho=\left(x^{2}+y^{2}\right)^{1 / 2}, \theta=\tan ^{-1}(y / x)$ and $j=\sqrt{-1}, R_{m, n}(\rho)$ is radial polynomial. The image function $\mathrm{f}(\mathrm{x}, \mathrm{y})$ can be represented as

$f(x, y)=\sum_{m} \sum_{n} A_{m, n} V_{m, n}(x, y)$

Modified radial polynomial can be expressed as

$A_{m, n}=\frac{p+1}{\pi} \sum_{j=o}^{N-1} \sum_{k=0}^{N-1} f\left(x_{j}, y_{k}\right) V_{m, n}^{*}\left(x_{j}, y_{k}\right) \Delta^{2}$

Here $\Delta=\frac{2}{D}$

\subsection{Zernike Moment}

The proposed method has been applied to capture the pattern and edge qualities of the image. It is well defined that Zernike polynomials are orthogonal to each other, these moments can characterize the qualities of an image with no idleness or coincide of facts between the moments. Because of these unique properties, these features have broadly been used in different types of 
applications [19][25]. It has been used in pattern-based image recovery in edge detection and like a feature set in model recognition .

The Zernike polynomials are orthogonal.Therefore it can draw out the Zernike moments from a ROI irrespective of the shape of the target[14]. The formulation of Zernike moment appears to be very favored, outperforming the options (in phrase of noise resilience, information redundancy and reconstruction capability).

Complex Zernike Plynomial for a distinct image using current pixel $\mathrm{f}(\mathrm{x}, \mathrm{y})$ are explained as $R_{m, n}^{Z}(\rho)=\sum_{s=0}^{(m-|n|) 2} \frac{(-1)^{s}(p-s) ! \rho^{m-2 s}}{s !\left(\frac{m+|n|}{2}-s\right) !\left(\frac{m-|n|}{2}-s\right) !}$

where $|n| \leq m$ and $m-|n|=$ even

\subsection{Psuedo Zernike Polynomial}

$R_{m, n}^{P}(\rho)=\sum_{s=0}^{(m-|m|)} \frac{(-1)^{s}(2 p+1-s) ! \rho^{m-s}}{s !(m+|n|+1-s) !(m-|n|-s) !}$

where $m \leq n$

\subsection{Orthogonal Furier -Mellin Plynomial}

$R_{m}^{F}(\rho)=\sum_{s=0}^{m} \frac{(-1)^{s+m}(m+1+s) ! \rho^{s}}{s !(m-s) !(s+1) !}$

Since OFMPs are independent of $n$, unlike ZMs and PZMs.

For the computation of the moments, the image (or area of focus) is initially mapped to the unit disc operating polar coordinates $(\rho, \theta)$, in which the middle of the test image is the source of the unit disc. Limited measures of ORIM at various orders $(\mathrm{n}=2,4,8,16,31,64,128,256)$ have been taken. 


\section{Feature Selection using Particle Swarm Optimization (PSO)}

If $\mathrm{L}$ be a dataset of $\mathrm{R}$ images with dimensions of $\mathrm{P}$ which is defined as $\mathrm{L}=\mathrm{R} * \mathrm{P}$ array. The aim of the feature (moment) set choice is to get $\mathrm{p}$ size out of the total feature (moments) area where $\mathrm{p}<\mathrm{P}$, that optimizes a function $\mathrm{A}(\mathrm{X})$. There are two types of features one is of best features and other is local feature in the subgroup. $\mathrm{F}$ is features sets of the melanoma images feature subset $\mathrm{S} \subseteq \mathrm{F}$ and $\mathrm{S}=\mathrm{p}$ which enhances the condition feature i.e.

$$
A(S)=\max _{Y \subseteq F} A(Y)
$$

Unluckily, not any single technique occurs for computing the standard of the feature set that works best for all melanoma images. Accuracy is the mainly used decisive factor function for the assessment of categorization models. In this method, the precision of the categorization bought through a feature set $\mathrm{S}$, that is described as fitness factor. This technique developed by Kennedy and Eberhart in 1995[26]. Such as different natural techniques, PSO additionally utilizes a group of potential solutions to search the study space. Therefore, the company inside the community is presumed to "fly" through all search house so as to search out a offering area of the situation. Try to let, particle ' $\mathrm{i}$ ' of the swarm be depicted by the perspective vector $\mathrm{x}_{\mathrm{i}}=\left(\mathrm{x}_{\mathrm{i} 1}, \mathrm{x}_{\mathrm{i} 2}, \ldots, \mathrm{x}_{\mathrm{id}}\right)$ and the ideal particle of the swarm, is represented by the index $g$. The finest past position of particle $i$ is captured and listed as $\mathrm{p}_{\mathrm{i}}=\left(\mathrm{p}_{\mathrm{i} 1}, \mathrm{p}_{\mathrm{i} 2}, \ldots, \mathrm{p}_{\mathrm{id}}[26],[27]\right.$. The location alter of particle $\mathrm{i}$ is $\mathrm{Vi}=\left(\mathrm{V}_{\mathrm{i} 1}, \mathrm{~V}_{\mathrm{i} 2}\right.$, ..., $\mathrm{V}_{\text {id }}$. Particles modify the velocity and position throughout searching two kinds of 'best' value. Among its personal best (pbest), that is the position of its maximum fitness value[28]The other is the universal best (gbest), that is the position of total finest value, bought by any particles in the population. Particles upgrade their unique positions and velocities in accordance to the following equations:

$\left.\mathrm{v}_{\mathrm{j}}(\mathrm{i})=\mathrm{wv}_{\mathrm{j}}(\mathrm{i}-1)+\mathrm{r}_{1} \mathrm{c} 1\left(\mathrm{p}_{\text {best }} \mathrm{j}\right)-\mathrm{x}_{\mathrm{j}}(\mathrm{i})\right)+\mathrm{r}_{2} \mathrm{c} 2\left(\mathrm{~g}_{\text {best }}-\mathrm{x}_{\mathrm{j}}(\mathrm{i})\right)$ 


$$
\mathrm{p}_{\mathrm{j}}(\mathrm{i})=\mathrm{p}_{\mathrm{j}}(\mathrm{i}-1)+\mathrm{v}_{\mathrm{j}}(\mathrm{i})
$$

In which, $v_{j}(i)$ is the speed of the jth particle in the ith iteration, $p_{j}(i)$ is the similar position, pbest and gbest similar individual local best and global best respectively, the parameter $\mathrm{w}$ is the inertia weight, and $\mathrm{c} 1$ and $\mathrm{c} 2$ are the accelerate parameters and $\mathrm{r}_{1}$ and $\mathrm{r}_{2}$ are arbitrary constant values . $w=(w-0.4) *($ Maxitr - Itr $) /$ Maxitr +0.4

The inertia weight reduces through the iterations, differing from 1.4 to 0.4 according to the previous formula. The flow chart of PSO centered feature collection[30] has confirmed in on top Fig. When most of our test, we operate the same setup of the PSO algorithm variables so as to enhances the robustness of the contrast around various other techniques. In specific problem, parameters are taken such as , $\mathrm{D}=100 ; \mathrm{c} 1=2 ; \mathrm{c} 2=2 ; \omega \max =1.4 ; \omega \min =0.4$, and Maxitr=200 in the PSO parametric quantity set.

\section{Support Vector Machine (SVM) Classifier}

Generally different techniques are available to train and verify the precision of a categorization version. In this research, two methods have been used. One specific technique is to separate the information setup into 2 different sets referred to as training and test units. Then the classification system is trained by using the training set and validate through sub-testing from the test set[29]. One more typically applied strategy in classification system is that the 5 fold cross-validation technique. Using this technique, the dataset of magnitutde of ZM,PZM,OFFM is separated into nalike subsets. Then, n-units of training/testing are usually done, wherever in every spherical, n-1 units tend to be applied for training the system and also the left nth subset is range in concerning the super-plane and additionally the nearby datum to every category[28]. The selection attribute made merely the SVM classifier for a couple of problems are often developed, employing a kernel 
perform $\mathrm{K}\left(\mathrm{x}, \mathrm{x}_{\mathrm{i}}\right)$ like analogue and radial basis function $(\mathrm{RBF})$ to a replacement trial $\mathrm{x}$ and $\mathrm{a}$ training pattern $\mathrm{x}_{\mathrm{i}}$ as given bellow:

$$
f(x)=\sum_{i} \alpha_{i} y_{j} K\left(x, x_{i}\right)+\alpha_{0}, \alpha_{i} \geq 0 \forall i
$$

Where $\mathrm{y}_{\mathrm{i}}= \pm 1$ the mark of trial $\mathrm{x}_{\mathrm{i}}$. The variables $\alpha_{i} \geq 0$ are optimized through the training process.

\section{Results and Discussion}

In the proposed work a set of 570 melanoma and 250 non-melanoma images are taken from ISIB2016 [24] database. All Images are of the same size .

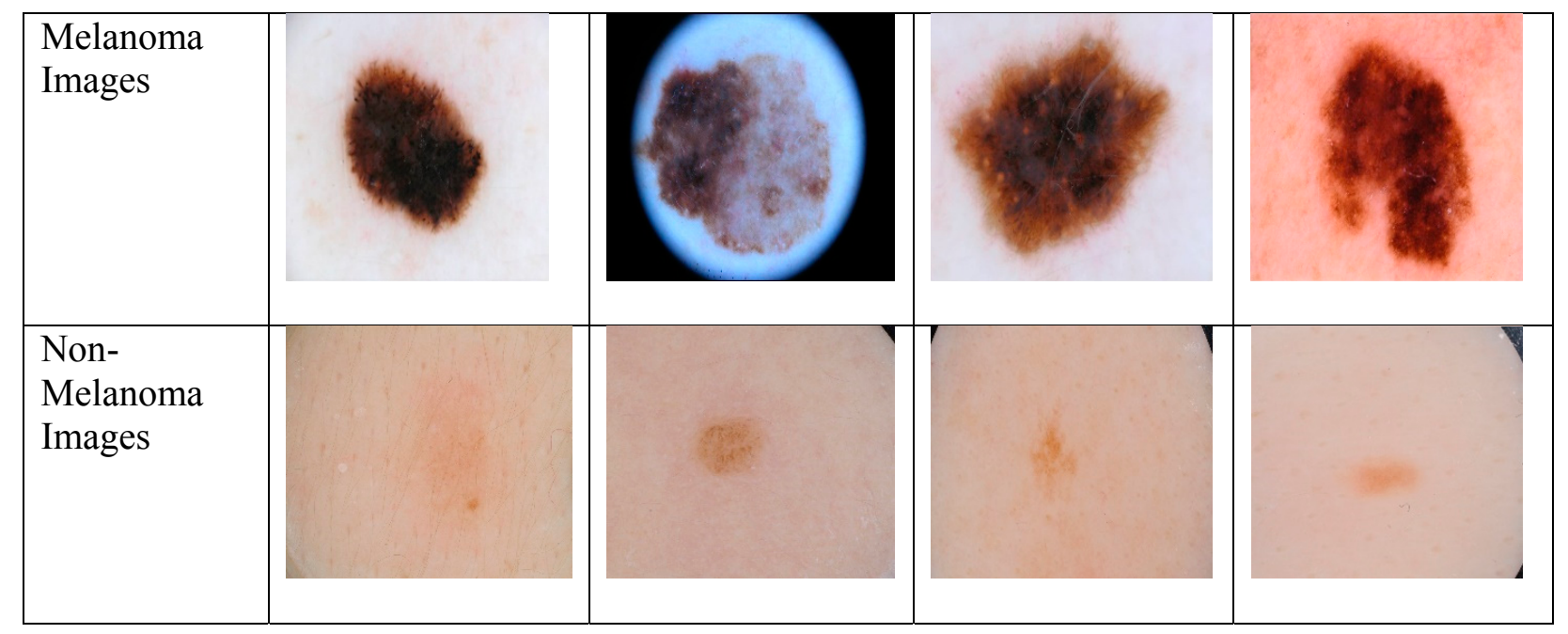

Figure: 3 Examples of Melanoma and No-melanoma Images

Table 1: Orthogonal Moments Comparision for Melanoma Image

\begin{tabular}{|c|c|c|c|}
\hline Phase & Zernike Moment (ZM) & Psudo Zernike Moment & Orthogonal Furier-Mellin \\
angel & & $($ PZM) & moments (OFMM) \\
$(\phi)$ & & & \\
\hline
\end{tabular}




\begin{tabular}{|c|c|c|c|c|c|c|c|c|c|}
\hline & $\begin{array}{c}\text { Norm } \\
\text { alized } \\
\text { ZM }\end{array}$ & $\begin{array}{c}\text { Magnit } \\
\text { ude of } \\
\text { ZM }\end{array}$ & $\begin{array}{l}\text { Elapse } \\
\text { d time } \\
\text { (Sec.) }\end{array}$ & $\begin{array}{l}\text { Norm } \\
\text { alized } \\
\text { PZM }\end{array}$ & $\begin{array}{l}\text { Magnit } \\
\text { ude of } \\
\text { PZM }\end{array}$ & $\begin{array}{l}\text { Elapse } \\
\text { d time }\end{array}$ & $\begin{array}{c}\text { Normalized } \\
\text { OFMM }\end{array}$ & $\begin{array}{c}\text { Magnitud } \\
\text { e of } \\
\text { OFMM }\end{array}$ & $\begin{array}{l}\text { Elapse } \\
\text { d time }\end{array}$ \\
\hline \multicolumn{10}{|c|}{$\mathrm{N}=2$ order of moment } \\
\hline $10^{\circ}$ & $\begin{array}{l}9.197+ \\
03\end{array}$ & $\begin{array}{l}4.789 \mathrm{e} \\
+07\end{array}$ & 0.0291 & 1.738 & $\begin{array}{l}9.054 \mathrm{e} \\
+03\end{array}$ & 0.021 & $\begin{array}{l}-0.063+ \\
0.051 \mathrm{i}\end{array}$ & $1.280+03$ & 0.020 \\
\hline $20^{\circ}$ & $\begin{array}{l}2.394 \mathrm{e} \\
+04\end{array}$ & $\begin{array}{l}1.701+ \\
08\end{array}$ & 0.0269 & 2.320 & $\begin{array}{l}1.655 \mathrm{e} \\
+04\end{array}$ & 0.021 & $\begin{array}{l}-0.081+ \\
0.090 \mathrm{i}\end{array}$ & $2.603 \mathrm{e}+03$ & 0.037 \\
\hline $30^{\circ}$ & $\begin{array}{l}3.874 \mathrm{e} \\
+04\end{array}$ & $\begin{array}{l}3.324 \mathrm{e} \\
+08\end{array}$ & 0.0316 & 2.652 & $\begin{array}{l}2.275 \mathrm{e} \\
+04\end{array}$ & 0.021 & $\begin{array}{l}-0.052+ \\
0.096 \mathrm{i}\end{array}$ & $2.812 \mathrm{e}+03$ & 0.031 \\
\hline $40^{\circ}$ & $\begin{array}{l}4.753 \mathrm{e} \\
+04\end{array}$ & $\begin{array}{l}4.445 \mathrm{e} \\
+08\end{array}$ & 0.0396 & 2.703 & $\begin{array}{l}2.528 \mathrm{e} \\
+04\end{array}$ & 0.023 & $\begin{array}{l}-0.017+ \\
0.100 \mathrm{i}\end{array}$ & $2.855 \mathrm{e}+03$ & 0.028 \\
\hline \multicolumn{10}{|c|}{$\mathrm{N}=\mathbf{4}$ order of moment } \\
\hline $10^{\circ}$ & $\begin{array}{l}1.132 \mathrm{e} \\
+09\end{array}$ & $\begin{array}{l}1.005 \mathrm{e} \\
+12\end{array}$ & 0.0324 & 4.361 & $\begin{array}{l}1.362 \mathrm{e} \\
+04\end{array}$ & 0.024 & $\begin{array}{l}-0.068- \\
0.058 \mathrm{i}\end{array}$ & $1.405 \mathrm{e}+03$ & 0.021 \\
\hline $20^{\circ}$ & $\begin{array}{l}1.132 \mathrm{e} \\
+09\end{array}$ & $\begin{array}{l}4.846 \mathrm{e} \\
+12\end{array}$ & 0.0457 & 5.784 & $\begin{array}{l}2.475 \mathrm{e} \\
+04\end{array}$ & 0.026 & $\begin{array}{l}-3.184 \mathrm{e}+03 \\
-1.502 \mathrm{e}+03 \mathrm{i}\end{array}$ & $3.521 \mathrm{e}+03$ & 0.023 \\
\hline $30^{\circ}$ & $\begin{array}{l}2.210 \mathrm{e} \\
+09\end{array}$ & $\begin{array}{l}1.137 \mathrm{e} \\
+13\end{array}$ & 0.0515 & 6.653 & $\begin{array}{l}3.425+ \\
04\end{array}$ & 0.028 & $\begin{array}{l}-0.212- \\
0.060 \mathrm{i}\end{array}$ & $5.692 \mathrm{e}+03$ & 0.025 \\
\hline $40^{\circ}$ & $\begin{array}{l}1.655 \mathrm{e} \\
+13\end{array}$ & $\begin{array}{l}1.655 \mathrm{e} \\
+13\end{array}$ & 0.0598 & 6.745 & $\begin{array}{l}3.785 \mathrm{e} \\
+04\end{array}$ & 0.034 & $\begin{array}{l}-0.244- \\
0.023 \mathrm{i}\end{array}$ & $6.884 \mathrm{e}+03$ & 0.029 \\
\hline
\end{tabular}




\begin{tabular}{|c|c|c|c|c|c|c|c|c|c|}
\hline $10^{\circ}$ & $\begin{array}{l}2.730 \mathrm{e} \\
+17\end{array}$ & $\begin{array}{l}4.739 \mathrm{e} \\
+20\end{array}$ & 0.0476 & 13.994 & $\begin{array}{l}2.429 \mathrm{e} \\
+04\end{array}$ & 0.034 & $\begin{array}{l}0.046+ \\
0.028 \mathrm{i}\end{array}$ & $8.452 \mathrm{e}+02$ & 0.022 \\
\hline $20^{\circ}$ & $\begin{array}{l}1.760 \mathrm{e} \\
+18\end{array}$ & $\begin{array}{l}4.186 \mathrm{e} \\
+21\end{array}$ & 0.0653 & 18.963 & $\begin{array}{l}4.509 \mathrm{e} \\
+04\end{array}$ & 0.043 & $\begin{array}{l}0.077+ \\
0.011 \mathrm{i}\end{array}$ & $1.675 \mathrm{e}+03$ & 0.023 \\
\hline $30^{\circ}$ & $\begin{array}{l}4.930 \mathrm{e} \\
+18\end{array}$ & $\begin{array}{l}1.410 \mathrm{e} \\
+22\end{array}$ & 0.0792 & 21.737 & $\begin{array}{l}6.217 \mathrm{e} \\
+04\end{array}$ & 0.050 & $\begin{array}{l}0.070- \\
0.006 \mathrm{i}\end{array}$ & $1.834 \mathrm{e}+03$ & 0.025 \\
\hline $40^{\circ}$ & $\begin{array}{l}7.790 \mathrm{e} \\
+18\end{array}$ & $\begin{array}{l}2.428 \mathrm{e} \\
+22\end{array}$ & 0.0808 & 22.063 & $\begin{array}{l}6.878 \mathrm{e} \\
+04\end{array}$ & 0.064 & $\begin{array}{l}0.056- \\
0.006 \mathrm{i}\end{array}$ & $1.595 \mathrm{e}+03$ & 0.028 \\
\hline \multicolumn{10}{|c|}{$\mathrm{N}=\mathbf{1 6}$ order of moment } \\
\hline $10^{\circ}$ & $\begin{array}{l}1.276 \mathrm{e} \\
+35\end{array}$ & $\begin{array}{l}1.172 \mathrm{e} \\
+38\end{array}$ & 0.0801 & 49.957 & $\begin{array}{l}4.590 \mathrm{e} \\
+04\end{array}$ & 0.088 & $\begin{array}{l}0.022- \\
0.009 \mathrm{i}\end{array}$ & $3.470 \mathrm{e}+02$ & 0.023 \\
\hline $20^{\circ}$ & $\begin{array}{l}2.820 \mathrm{e} \\
+36\end{array}$ & $\begin{array}{l}3.550 \mathrm{e} \\
+39\end{array}$ & 0.1283 & 67.587 & $\begin{array}{l}8.508 \mathrm{e} \\
+04\end{array}$ & 0.098 & $\begin{array}{l}0.016+ \\
0.002 \mathrm{i}\end{array}$ & $3.487 \mathrm{e}+02$ & 0.024 \\
\hline $30^{\circ}$ & $\begin{array}{l}1.622 \mathrm{e} \\
+37\end{array}$ & $\begin{array}{l}2.457 \mathrm{e} \\
+40\end{array}$ & 0.1590 & 77.652 & $\begin{array}{l}1.175 \mathrm{e} \\
+05\end{array}$ & 0.114 & $\begin{array}{l}0.017- \\
0.002 \mathrm{i}\end{array}$ & $4.664 \mathrm{e}+02$ & 0.033 \\
\hline $40^{\circ}$ & $\begin{array}{l}3.607 \mathrm{e} \\
+37\end{array}$ & $\begin{array}{l}5.953 \mathrm{e} \\
+40\end{array}$ & 0.1607 & 78.864 & $\begin{array}{l}1.301 \mathrm{e} \\
+05\end{array}$ & 0.090 & $\begin{array}{l}0.019+ \\
0.006 \mathrm{i}\end{array}$ & $5.783 \mathrm{e}+02$ & 0.027 \\
\hline \multicolumn{10}{|c|}{$\mathrm{N}=32$ order of moment } \\
\hline $10^{\circ}$ & $\begin{array}{l}1.755 \mathrm{e} \\
+70\end{array}$ & $\begin{array}{l}8.308 \mathrm{e} \\
+72\end{array}$ & 0.1380 & $\begin{array}{l}- \\
1.885 \mathrm{e} \\
+07\end{array}$ & $\begin{array}{l}8.927 \mathrm{e} \\
+09\end{array}$ & 0.102 & $\begin{array}{l}0.001- \\
0.001 \mathrm{i}\end{array}$ & 34.916 & 0.023 \\
\hline
\end{tabular}




\begin{tabular}{|c|c|c|c|c|c|c|c|c|c|}
\hline $20^{\circ}$ & $\begin{array}{l}4.739 \mathrm{e} \\
+72\end{array}$ & $\begin{array}{l}3.073+ \\
75\end{array}$ & 0.2412 & $\begin{array}{l}- \\
2.731 \mathrm{e} \\
+07\end{array}$ & $\begin{array}{l}1.771 \mathrm{e} \\
+10\end{array}$ & 0.139 & $\begin{array}{l}0.006- \\
0.0004 \mathrm{i}\end{array}$ & $1.317 \mathrm{e}+02$ & 0.035 \\
\hline $30^{\circ}$ & $\begin{array}{l}1.164 \mathrm{e} \\
+74\end{array}$ & $\begin{array}{l}9.085 \mathrm{e} \\
+76\end{array}$ & 0.2608 & $\begin{array}{l}- \\
4.008 \mathrm{e} \\
+07\end{array}$ & $\begin{array}{l}3.126 \mathrm{e} \\
+10\end{array}$ & 0.170 & $\begin{array}{l}0.005+ \\
0.0007 \mathrm{i}\end{array}$ & $1.388 \mathrm{e}+02$ & 0.028 \\
\hline $40^{\circ}$ & $\begin{array}{l}5.160 \mathrm{e} \\
+74\end{array}$ & $\begin{array}{l}4.387 \mathrm{e} \\
+77\end{array}$ & 0.2589 & $\begin{array}{l}- \\
3.808 \mathrm{e} \\
+07\end{array}$ & $\begin{array}{l}3.237 \mathrm{e} \\
+10\end{array}$ & 0.174 & $\begin{array}{l}1.258 \mathrm{e}+02- \\
4.723 \mathrm{e}-01 \mathrm{i}\end{array}$ & $1.258 \mathrm{e}+02$ & 0.029 \\
\hline \multicolumn{10}{|c|}{$\mathrm{N}=64$ order of moment } \\
\hline $10^{\circ}$ & $\begin{array}{l}2.672 \mathrm{e} \\
+140\end{array}$ & $\begin{array}{l}5.177 \mathrm{e} \\
+142\end{array}$ & 0.2672 & $\begin{array}{l}- \\
1.725 \mathrm{e} \\
+31\end{array}$ & $\begin{array}{l}4.147 \mathrm{e} \\
+33\end{array}$ & 0.268 & $\begin{array}{l}5.868 \mathrm{e}-04- \\
8.178 \mathrm{e}-04 \mathrm{i}\end{array}$ & 15.723 & 0.021 \\
\hline $20^{\circ}$ & $\begin{array}{l}8.967 \mathrm{e} \\
+144\end{array}$ & $\begin{array}{l}2.952 \mathrm{e} \\
+147\end{array}$ & 0.4553 & $\begin{array}{l}- \\
3.123 \mathrm{e} \\
+31\end{array}$ & $\begin{array}{l}1.028 \mathrm{e} \\
+34\end{array}$ & 0.268 & $\begin{array}{l}0.001+ \\
0.0001 \mathrm{i}\end{array}$ & 22.012 & 0.023 \\
\hline $30^{\circ}$ & $\begin{array}{l}4.083 \mathrm{e} \\
+147\end{array}$ & $\begin{array}{l}1.617 \mathrm{e} \\
+150\end{array}$ & 0.5281 & $\begin{array}{l}- \\
4.623 \mathrm{e} \\
+31\end{array}$ & $\begin{array}{l}1.830+ \\
34\end{array}$ & 0.305 & $\begin{array}{l}0.0015- \\
0.0001 \mathrm{i}\end{array}$ & 38.923 & 0.026 \\
\hline $40^{\circ}$ & $\begin{array}{l}7.222 \mathrm{e} \\
+148\end{array}$ & $\begin{array}{l}3.117 \mathrm{e} \\
+151\end{array}$ & 0.7580 & $\begin{array}{l}- \\
4.245 \mathrm{e} \\
+31\end{array}$ & $\begin{array}{l}1.832 \mathrm{e} \\
+34\end{array}$ & 0.321 & $\begin{array}{l}0.001- \\
0.0004 i\end{array}$ & 32.817 & 0.029 \\
\hline & & & & & & & & & \\
\hline
\end{tabular}




\begin{tabular}{|c|c|c|c|c|c|c|c|c|c|}
\hline $10^{\circ}$ & $\begin{array}{l}2.481 \mathrm{e} \\
+134\end{array}$ & $\begin{array}{l}4.324 \mathrm{e} \\
+140\end{array}$ & 0.2773 & $\begin{array}{l}- \\
0.725 \mathrm{e} \\
+22\end{array}$ & $\begin{array}{l}3.231 \mathrm{e} \\
+30\end{array}$ & 0.3763 & $\begin{array}{l}3.762 \mathrm{e}-03- \\
6.353 \mathrm{e}-02 \mathrm{i}\end{array}$ & 25.534 & 0.023 \\
\hline $20^{\circ}$ & $\begin{array}{l}8.967 \mathrm{e} \\
+92\end{array}$ & $\begin{array}{l}2.952 \mathrm{e} \\
+100\end{array}$ & 0.4653 & $\begin{array}{l}- \\
0.023 \mathrm{e} \\
+18\end{array}$ & $\begin{array}{l}1.143 \mathrm{e} \\
+26\end{array}$ & 0.5763 & $\begin{array}{l}0.003+ \\
0.004 i\end{array}$ & 21.354 & 0.025 \\
\hline $30^{\circ}$ & $\begin{array}{l}4.083 \mathrm{e} \\
+88\end{array}$ & $\begin{array}{l}1.617 \mathrm{e} \\
+90\end{array}$ & 0.6781 & $\begin{array}{l}0.623 \mathrm{e} \\
+14\end{array}$ & $\begin{array}{l}1.534 \mathrm{e} \\
+23\end{array}$ & 0.5463 & $\begin{array}{l}0.175- \\
0.362 \mathrm{i}\end{array}$ & 37.635 & 0.036 \\
\hline $40^{\circ}$ & $\begin{array}{l}7.222 \mathrm{e} \\
+78\end{array}$ & $\begin{array}{l}3.117 \mathrm{e} \\
+82\end{array}$ & 0.7580 & $\begin{array}{l}1.246 \mathrm{e} \\
+12\end{array}$ & $\begin{array}{l}1.753 \mathrm{e} \\
+18\end{array}$ & 0.6324 & $\begin{array}{l}0.003- \\
0.002 \mathrm{i}\end{array}$ & 31.356 & 0.056 \\
\hline \multicolumn{10}{|c|}{$\mathrm{N}=256$} \\
\hline $10^{\circ}$ & $\begin{array}{l}3.232 \mathrm{e} \\
+79\end{array}$ & $\begin{array}{l}5.177 \mathrm{e} \\
+80\end{array}$ & 0.2522 & $\begin{array}{l}1.625 \mathrm{e} \\
+08\end{array}$ & $\begin{array}{l}3.634 \mathrm{e} \\
+33\end{array}$ & 0.4653 & $\begin{array}{l}1.242 \mathrm{e}+02- \\
2.354 \mathrm{e}+02 \mathrm{i}\end{array}$ & 18.456 & 0.076 \\
\hline $20^{\circ}$ & $\begin{array}{l}8.967 \mathrm{e} \\
+73\end{array}$ & $\begin{array}{l}2.952 \mathrm{e} \\
+76\end{array}$ & 0.6453 & $\begin{array}{l}1.253 \mathrm{e} \\
+06\end{array}$ & $\begin{array}{l}1.635 \mathrm{e} \\
+34\end{array}$ & 0.7835 & $\begin{array}{l}2.523 \mathrm{e}+03+ \\
1.253 \mathrm{e}+02 \mathrm{i}\end{array}$ & 24.576 & 0.083 \\
\hline $30^{\circ}$ & $\begin{array}{l}4.083 \mathrm{e} \\
+70\end{array}$ & $\begin{array}{l}1.617 \mathrm{e} \\
+75\end{array}$ & 0.7880 & $\begin{array}{l}1.364 \mathrm{e} \\
+04\end{array}$ & $\begin{array}{l}1.543+ \\
34\end{array}$ & 0.7265 & $\begin{array}{l}1.654 \mathrm{e}+03- \\
1.753 \mathrm{e}+03 \mathrm{i}\end{array}$ & 40.564 & 0.078 \\
\hline $40^{\circ}$ & $\begin{array}{l}5.265 \mathrm{e} \\
+67\end{array}$ & $\begin{array}{l}3.117 \mathrm{e} \\
+68\end{array}$ & 0.8681 & $\begin{array}{l}1.543 \mathrm{e} \\
+04\end{array}$ & $\begin{array}{l}1.763 \mathrm{e} \\
+34\end{array}$ & 0.8263 & $\begin{array}{l}3.536 \mathrm{e}+04- \\
4.653 \mathrm{e}+04 \mathrm{i}\end{array}$ & 33.475 & 0.088 \\
\hline
\end{tabular}

Table 2 Classification results of Melanoma Images

\begin{tabular}{|c|c|c|c|}
\hline Techniques & Accuracy & Specificity & Sensitivity \\
\hline Sheha et al.[30] & 89.30 & 82.60 & 84.00 \\
\hline
\end{tabular}




\begin{tabular}{|c|c|c|c|}
\hline Silvio M. et al. [31] & $81.9 \%$ & $72.21 \%$ & $84.76 \%$ \\
\hline Proposed Model & $\mathbf{9 1 . 2 4 \%}$ & $\mathbf{8 8 . 7 6 \%}$ & $\mathbf{8 6 . 7 8 \%}$ \\
\hline
\end{tabular}

In this paper three orthogonal moments have been investigated as shown in table 1. Melanoma images are analysed by rotating the image phase for each order of moment.

From the table1 moments of the melanoma images are investigated for different orders and phase angles. The range of order is $2,4,8,16,32,64,128,256$ for each order phase angle varied from $10^{\circ}$ to $40^{\circ}$. From the table1 it is confirmed that as order of moment increased from 2 to 256 , the magnitude of $\mathrm{ZM}$ and normalized $\mathrm{ZM}$ is increased up to $\mathrm{N}=64$ and after $\mathrm{N}=64$ it started to decrease as shown in table1. Magnitude of PZM and normalized PZM is increased up to $\mathrm{N}=64$, after $\mathrm{N}=64$ the magnitude started to decreases as shown in table1. The magnitude of OFMM is gradualy increased upto $\mathrm{N}=8$, after $\mathrm{N}=8$ magnitude started to deacrease.

It is observed from table1 that by increasing the order of moments the magnitude of ZM,PZM increased means the information of images increased and hence easy to classify the melanoma images. At $\mathrm{N}=64$ the obtained moments are more significant because the magnitude of ZM, PZM is maximum. For the classification 100 melanoma and 100 non-melanoma images have been used. These images have been classified using SVM and compared the results with other existing technique as shown in table 2.The performance of the proposed technique is found better than earlier two techniques as shown in table 2.

From the table first technique [30] has been tested for 20 images, while the second technique [31] has been tested for 171 images. Thus the result obtained from the proposed technique is better and useful for the diagnosis of melanoma images. 
Classification performance is examined by the specificity, sensitivity, accuracy. If, it is verified skin image having melanoma then the considered as true positive (TP). If the skin image do not have melanoma and classified as true negative (TN). In the same way, when a melanoma is confirmed absent in a patient, the analysis examination indicates the illness is absent as well, the test outcome is true negative (TN). When the analysis test shows the bearing of melanoma in a skin image that actually has no such illness, the test result is false positive (FP). Furthermore, if the outcome of the analysis of experiments suggests that the illness is away for a skin image with melanoma for certain, the test outcome is false negative $(\mathrm{FN})$. Then

Sensitivity $=\mathrm{TP} /(\mathrm{TP}+\mathrm{FN})$

Specificity $=\mathrm{TN} /(\mathrm{TN}+\mathrm{FP})$

Accuracy $=(\mathrm{TN}+\mathrm{TP}) /(\mathrm{TN}+\mathrm{TP}+\mathrm{FN}+\mathrm{FP}$

Sensitivity is the proportion to true positives that are precisely determined by classification, It reveals exactly how effective the examination is performing. Specificity is the symmetry of the true negatives precisely determined by classification[35]. It implies exactly how good the testing is classified normal (negative) condition. Accuracy is symmetry of reliability outcomes, whether true positive or true negative, in a group. Sensitivity, specificity and accuracy of 570 melanoma images are $88.78 \%, 87.86 \%$ and $91.24 \%$ respectively are computed using RBF SVM which are better than linear SVM as shown in table 2.

\section{Conclusion}

In this paper a set of orthogonal moments have been proposed for classification of melanoma images. Moment invariants available in literature and past research haven not made any significant contribution in melanoma image classification. The proposed method is better as it has the ability to wipe off the symmetric entity of majority of the moments. These extracted moments are selected 
by using PSO, furthermore selected moments are classified by SVM. Classification rate of the proposed method is $91.24 \%$. It is clear from the obtatined simulation result that the obtained magnitude of ZM, and PZM of melanoma images at $\mathrm{N}=64$ found better as compared to lower and higher order. Poposed technique is superior than other existiting techniques. OMs are very sensitive to noise and nonredundant hence very limited moments are required for better classification as compare to the color featurs.

It is significan to classify the disease assessment in a better way by analyzing the image. Computer analysis available so far still need much specialized environment and tools especially for the less skilled skin experts. The proposed melanoma classification algorithm may be utilized for betterment to improve diagnostic accuacy of melanoma and hence the societal welfare.

\section{References}

[1] M. Rastgoo, R. Garcia, O. Morel, and F. Marzani, "Automatic differentiation of melanoma from dysplastic nevi,” Comput. Med. Imaging Graph., vol. 43, pp. 44-52, 2015.

[2] I. Maglogiannis and C. N. Doukas, "Overview of advanced computer vision systems for skin lesions characterization," IEEE Transactions on Information Technology in Biomedicine, vol. 13, no. 5. pp. 721-733, 2009.

[3] O. Abuzaghleh, B. D. Barkana, and M. Faezipour, "Noninvasive real-time automated skin lesion analysis system for melanoma early detection and prevention," IEEE J. Transl. Eng. Heal. Med., vol. 3, 2015.

[4] A. G. Manousaki et al., "A simple digital image processing system to aid in melanoma diagnosis in an everyday melanocytic skin lesion unit. A preliminary report," Int. J. Dermatol., vol. 45, no. 4, pp. 402-410, 2006.

[5] S. Bakheet, "An SVM Framework for Malignant Melanoma Detection Based on Optimized HOG Features," Computation, vol. 5, no. 1, p. 4, 2017.

[6] M. A. Marchetti et al., "Results of the 2016 International Skin Imaging Collaboration International Symposium on Biomedical Imaging challenge: Comparison of the accuracy of computer algorithms to dermatologists for the diagnosis of melanoma from dermoscopic images," Journal of the American Academy of Dermatology, 2017.

[7] S. Jain, V. Jagtap, and N. Pise, "Computer aided melanoma skin cancer detection using image processing," in Procedia Computer Science, 2015, vol. 48, no. C, pp. 736-741.

[8] R. B. Oliveira, J. P. Papa, A. S. Pereira, and J. M. R. S. Tavares, "Computational methods for pigmented skin lesion classification in images: review and future trends," Neural Comput. Appl., pp. 1-24, 2016.

[9] Z. Ping, H. Ren, J. Zou, Y. Sheng, and W. Bo, "Generic orthogonal moments: JacobiFourier moments for invariant image description," Pattern Recognit., vol. 40, no. 4, pp. 
1245-1254, 2007.

[10] R. Dhir, "Moment based invariant feature extraction techniques for Bilingual Character Recognition," ICETC 2010 - 2010 2nd Int. Conf. Educ. Technol. Comput., vol. 4, 2010.

[11] S. Urooj, S. P. Singh, and A. Q. Ansari, Computer Aided Detection of Breast Cancer using Pseudo Zernike Moment as a Texture Descriptors, vol. 651, no. March. 2013.

[12] S. P. Singh and S. Urooj, "Accurate and Fast Computation of Exponent Fourier Moment," Arab. J. Sci. Eng., vol. 42, no. 8, pp. 3299-3306, 2017.

[13] S. Dominguez, "Simultaneous recognition and relative pose estimation of 3D objects using 4D orthonormal moments," Sensors (Switzerland), vol. 17, no. 9, 2017.

[14] C. Singh and R. Upneja, "Error analysis in the computation of orthogonal rotation invariant moments," J. Math. Imaging Vis., vol. 49, no. 1, pp. 251-271, 2014.

[15] C. Kan and M. D. Srinath, "Invariant character recognition with Zernike and orthogonal Fourier-Mellin moments," Pattern Recognit., vol. 35, no. 1, pp. 143-154, 2002.

[16] H. Zhang, Z. Li, and Y. Liu, "Fractional orthogonal fourier-mellin moments for pattern recognition," in Communications in Computer and Information Science, 2016, vol. 662, pp. 766-778.

[17] H. Zhang, H. Z. Shu, P. Haigron, B. S. Li, and L. M. Luo, "Construction of a complete set of orthogonal Fourier-Mellin moment invariants for pattern recognition applications," Image Vis. Comput., vol. 28, no. 1, pp. 38-44, 2010.

[18] Y. Sheng and H. H. Arsenault, "Experiments on pattern recognition using invariant FourierMellin descriptors," J. Opt. Soc. Am. A, vol. 3, no. 6, p. 771, 1986.

[19] A. Khotanzad and Y. H. Hong, "Invariant Image Recognition by Zernike Moments," IEEE Trans. Pattern Anal. Mach. Intell., vol. 12, no. 5, pp. 489-497, 1990.

[20] T. V. Hoang and S. Tabbone, "Erratum: Generic orthogonal moments: Jacobi-Fourier moments for invariant image description (Pattern Recognition)," Pattern Recognition, vol. 46, no. 11. pp. 3148-3155, 2013.

[21] X. Li and A. Song, "A new edge detection method using Gaussian-Zemike moment operator," CAR 2010 - 2010 2nd International Asia Conference on Informatics in Control, Automation and Robotics, vol. 1. pp. 276-279, 2010.

[22] Z. Shao, H. Shu, J. Wu, B. Chen, and J. L. Coatrieux, "Quaternion Bessel-Fourier moments and their invariant descriptors for object reconstruction and recognition," Pattern Recognit., vol. 47, no. 2, pp. 603-611, 2014.

[23] J. Mennesson, C. Saint-Jean, and L. Mascarilla, "Color Fourier-Mellin descriptors for image recognition," Pattern Recognit. Lett., vol. 40, no. 1, pp. 27-35, 2014.

[24] Y. Sheng and L. Shen, "Orthogonal Fourier-Mellin moments for invariant pattern recognition," J. Opt. Soc. Am. A, vol. 11, no. 6, p. 1748, 1994.

[25] B. H. Shekar and D. S. Rajesh, "Affine Normalized Krawtchouk Moments Based Face Recognition," in Procedia Computer Science, 2015, vol. 58, pp. 66-75.

[26] F. Marini and B. Walczak, "Particle swarm optimization (PSO). A tutorial," Chemom. Intell. Lab. Syst., vol. 149, pp. 153-165, 2015.

[27] C. Tu, L. Chuang, J. Chang, and C. Yang, "Feature selection using PSO-SVM," IAENG Int. J. Comput. Sci., vol. 33, no. 1, pp. 1-6, 2007.

[28] H. Zeng and H. J. Trussell, "Feature selection using," IAENG Int. J. Comput. Sci., vol. 33, no. February, pp. 997-1000, 2006.

[29] J. Von Hagen, "Money growth targeting by the bundesbank*," J. Monet. Econ., vol. 43, no. 3, pp. 681-701, 1999. 
[30] M. Sheha, M. Mabrouk, and A. Sharawy, "Automatic detection of melanoma skin cancer using texture analysis," Int. J. Comput. ..., vol. 42, no. 20, pp. 22-26, 2012.

[31] S. M. Pereira, M. A. C. Frade, R. M. Rangayyan, and P. M. Azevedo-Marques, "Classification of color images of dermatological ulcers," IEEE J. Biomed. Heal. Informatics, vol. 17, no. 1, pp. 136-142, 2013. 